\title{
The American Experience With Desmopressin
}

David A. Bloom, M.D.

Summary: Conclusive evidence of a polyuric etiology from a failure of vasopressin elevation led to a new pharmacologic approach to the treatment of childhood nocturnal enuresis. Desmopressin acetate, a vasopressin analogue, has been used successfully since 1978 to treat this condition. Desmopressin's efficacy at doses of 5 to $40 \mu \mathrm{g}$ has been demonstrated in Europe and the United States. Similarly, its safety has been established, and it is a first-line choice for physicians worldwide.

\section{Introduction}

B edwetting is an integral, normal part of development in young children in whom sleep duration may exceed bladder capacity and arousal mechanisms may be immature. In fact, deferred nocturnal vasopressin amplification is probably an important physiologic device in young children, and physicians should generally be reluctant to consider nocturnal enuresis a condition requiring medical attention in children under 7 years of age.

Management choices presently available for nocturnal enuresis can be grouped into three categories. The first is actually no management, i.e., waiting for

Associate Professor of Surgery

Chief of Pediatric Urology

University of Michigan

Ann Arbor, Michigan

Address correspondence to: David A. Bloom, M.D., Associate Professor of Surgery, Chief of Pediatric Urology, University of Michigan, $1500 \mathrm{E}$. Medical Center Drive, Ann Arbor, MI 48109-0330 spontaneous resolution, which is likely in most children, particularly in the first 7 years of life. Attempting to achieve control in very young children is inadvisable: fluid restriction usually offers no relief, lifting at night is often unnecessarily disruptive to parents as well as children, and discipline is only to be condemned.

In some children with nocturnal enuresis, particularly those over 7 years of age, the potential for loss of self-esteem and social stigmatization may make intervention a logical choice. In such cases, a bell and pad moisture-sensing device, or alarm, is a typical starting point. Prerequisites for using alarms are a motivated child and family. Even then, this technique may be ineffective, and when the bedwetter must share a room, alarms are less practical.

The third option is medical intervention, i.e., augmenting nocturnal water conservation with the use of a vasopressin analogue such as desmopressin acetate.

An overview of the American experience with desmopressin is presented here.

\section{Early Inquiry and Treatment}

In 1897, in The Diseases of Infancy and Childhood, ${ }^{1}$ which is the classic and perhaps best early American pediatric textbook, L. Emmett Holt, an eminent pediatrician in New York City, discussed the manifold aspects of nocturnal enuresis. Holt recognized several causes for nocturnal enuresis. He did not anticipate the polyuric explanation favored today but thought instead that, when the urine itself was the causative factor, it was because of acidity. Other possible causes considered by Holt included constitutional disease, neurosis, phimosis, pinworms, and bladder calculus. Among acceptable treatments Holt listed meatotomy, circumcision, urine alkalinization, and the use of galvanism, belladonna, and strychnine. After Holt, the pharmacologic treatment of nocturnal enuresis remained largely empirical until the demonstration of a polyuric etiology from a failure of nocturnal vasopressin elevation. ${ }^{2}$ 


\section{Clinical Trials With Desmopressin}

Desmopressin acetate (DDAVP), a vasopressin analogue, was initially used with great success in children with diabetes insipidus. ${ }^{3}$ The first clinical trials that used intranasal desmopressin to treat bedwetting in children were conducted in Europe in 1978. In a Swedish study of 18 children with primary nocturnal enuresis, ${ }^{4}$ Tuvemo reported excellent results in eight children, relatively good results in eight, and unsatisfactory results in two. Desmopressin was used in a $20 \mu \mathrm{g} /$ day dosage. Birkásová et $\mathrm{al}^{5}$ used desmopressin at dosages of 10 and 40 $\mu \mathrm{g}$ to treat 22 Czechoslovakian children (mean age, $6.6 \pm 2.9$ years) with persistent nocturnal enuresis. Eighteen children responded favorably to the drug. Five of these who received the $40-\mu \mathrm{g}$ dose had a "dramatic" response.

At the time of these studies, the primary nonpharmacologic tool for nocturnal enuresis was the moisture-sensing alarm and the main therapeutic agent was imipramine. ${ }^{6}$ Imipramine, which has both central nervous and bladder actions, continues to be widely used for this purpose today. Oxybutynin chloride, an anticholinergic, is also effective but in a lesser number of children; the most likely to benefit from this agent are patients with detrusor instability, a relatively uncommon cause of isolated nocturnal enuresis.

No evidence of any major differences in toilet training habits or bedwetting patterns has been noted between Western European and North American children. Consequently, the American experience with desmopressin for nocturnal enuresis has generally followed the lead of European investigators. In 1983, Post et al reported an American double-blind, crossover study of desmopressin for nocturnal enuresis in 52 patients at three medical centers. ${ }^{7}$ Results demonstrated a $75 \%$ reduction in the frequency of wet nights; no patient had significant side effects. The best response, achieved in $12 \%$ of the children, was defined as 13 to 14 dry nights in the 2-week treatment period. Dosages were 20 and $40 \mu \mathrm{g} /$ day. The drug appeared most effective in children over 9 years of age, among whom $71 \%$ responded with 8 to 14 dry nights in the 2-week test. The larger dose was more effective in reducing the number of wet nights than the lower dose.

In 1989, Klauber reviewed 12 placebo-controlled trials conducted at 15 sites worldwide and consisting of 495 children and 21 adults. ${ }^{8}$ The three American trials in that review included $276 \mathrm{pa}-$ tients at multiple study sites. Almost all patients had been resistant to prior therapy. Desmopressin doses were 20 to $40 \mu \mathrm{g}$ administered intranasally. Results, reported as the percent fewer wet nights while taking desmopressin, varied from $24 \%$ to $65 \%$ with an average of $28.6 \%$. For example, in one of the trials using $40 \mu \mathrm{g}$ of desmopressin, there was a reduction of 3.7 wet nights compared with baseline in the initial 2 weeks of treatment, and a further reduction of 0.5 wet nights in the second 2 weeks for a total mean reduction of $4.2(34 \%)$ wet nights for the study period. This result was not seen with either placebo or the 20$\mu \mathrm{g}$ dose. Klauber commented that "there are many problems and variables with drug trials in enuresis." Patients most likely to be included in such trials have had the most intractable disease states and generally have been unresponsive to previous therapy. These patients can be expected to have less response to medication than unselected or previously untreated patients. Even so, after analysis of the many different studies, Klauber concluded that desmopressin unquestionably increased the number of dry nights in bedwetters compared with their own baselines and placebo. The 40- $\mu \mathrm{g}$ dose seemed to be more effective than $20 \mu \mathrm{g}$ and the drug appeared to be safe: there were no serious adverse reactions in the 516 patients. Importantly, almost all were resistant to previous treatment for nocturnal enuresis.

Miller, Goldberg, and Atkin, also in 1989, reported on the use of $40 \mu \mathrm{g}$ of desmopressin in 55 children ( 46 boys, 9 girls) with nocturnal enuresis. ${ }^{9}$ The patients were 6 to 17 years old and all were frequent bedwetters (3 or more nights/week) except for one girl ( 2 nights/week) and all had been refractory to other prior therapies. A positive response was defined as a reduction of wet nights by at least $50 \%$ or a decrease in the amount of wetness of the bed or pad in terms of parental perception. After a positive response was identified, the dose was systematically titrated down. In this 8-year study, four patient groups were recognized: nonresponders (19), partial responders (8), full responders on desmopressin (13), and full responders who had discontinued treatment and remained dry (15). Among the responders who remained dry off desmopressin, the duration of therapy varied from 3 to 36 months (average, 13.5) and the dry time off therapy was 6 to 84 months (average, 43). The responders still receiving desmopressin had therapy durations of 3 to 42 months (average, 9.9 months).

Miller and Klauber's 1990 update of these American trials confirmed the safety and efficacy of desmopressin. ${ }^{10}$ In two US multicenter studies, 176 children with 
primary nocturnal enuresis received 20 or $40 \mu \mathrm{g}$ of desmopressin or placebo for 4 weeks. This double-blind treatment phase was followed by a 4-week, open-label period during which all patients received either 20 or $40 \mu \mathrm{g}$ of the drug. Children on desmopressin had significantly fewer wet nights than those on placebo, and those crossed over from placebo to desmopressin showed similar reductions in nocturnal enuresis. Desmopressin was more effective at the higher dose. In 1992, Miller, Atkin, and Moody surveyed the previous experience with desmopressin and added their own findings. ${ }^{11}$ They found desmopressin most effective at the $40-\mu \mathrm{g}$ dose. Once dryness was attained, the dose was titrated downward.

Although not a clinical trial, a single-center experience with desmopressin revealed a substantial number of children dry at the low desmopressin dose of $5 \mu \mathrm{g} .{ }^{12}$ As in the initial European experience, desmopressin was used when other therapeutic modalities failed on the assumption that at least some of the children with refractory nocturnal enuresis had, in a sense, nephrogenic diabetes insipidus. In the absence of any other delivery system, the rhinal tube was utilized with initial dosing at $5 \mu \mathrm{g}$ and titrated upward as needed. Approximately $25 \%$ of the patients improved and were maintained on the $5-\mu \mathrm{g}$ dose and more than half were maintained effectively on $10 \mu \mathrm{g}$. The criteria for success in this group of children was defined as a decrease in the number of recorded wet nights per week. During treatment, 54\% of the children reported complete nighttime dryness and 38\% had a decrease in wet nights. These data suggest a relatively low dose of desmopressin is effective in some children. The advantage of low dosing is primarily that of cost. The $5-\mu \mathrm{g}$ rhinal tube is difficult to use, however, and when the spray applicator became commercially available in 1989, convenience overcame cost, and $10 \mu \mathrm{g}$ became the standard minimum dose.

\section{Treatment Considerations}

\section{Efficacy/Safety}

The efficacy of desmopressin has been substantiated by 14 years of Western European and North American clinical experience with the drug. In many centers, it has become the pharmacologic agent of first choice and its safety with careful use was established during those years. Rare reports of serious side effects indicate that cystic fibrosis, nasal polyps, and unmonitored, unsupervised usage are contraindications to desmopressin therapy ${ }^{13-15}$ Patients and families should be given a handout explaining the rules of treatment and signs of complications. Soon after therapy has begun, we check a morning set of electrolytes and monitor patients for dosing adjustments.

\section{Expectations}

Disparate definitions of satisfactory effect and flexible interpretations of data complicate most pharmacologic studies of nocturnal enuresis. The hope for a bedwetter who is brought to treatment is that the problem will be solved. It is clear from the literature, however, that this expectation is not always realized, although the problem is likely to be improved. For this reason, it is mandatory to have some objective sense of the magnitude of the bedwetting, i.e., how many wet nights a week a given child typically experiences. This information may be difficult to elicit given the variability of symptoms in some children, the denial of enu- resis in others, and the unwillingness of child or family to keep an elimination diary. Nevertheless, therapy should be unthinkable without a careful elimination history that includes documentation of the degree of incontinence. ${ }^{16}$

\section{Conclusion}

Staying dry through the night is a function of maturation, which varies from child to child; not all bedwetters require therapy. The majority of bedwetters seem to have a nocturnal polyuric factor that is amenable to replacement therapy with a vasopressin analogue such as desmopressin acetate. The American experience with desmopressin substantiates the European experience: desmopressin is an effective agent for the treatment of nocturnal enuresis and is a first-line choice for physicians worldwide.

In a larger context, William Carlos Williams, a poet and physician from New Jersey, described the discovery of this continent in terms of the ambiguity of wetness and dryness: "The New World, existing in those times beyond the sphere of all things known to history, lay in the fifteenth century as the middle of the desert or the sea ..." 17 In a smaller sense we recapitulate a bit of that dichotomy; over the long run in life we prefer to stand on dry land and to sleep in dry beds, but sometimes along the way circumstances and homeostasis tolerate and even demand the wet milieu.

\section{REFERENCES}

1. Holt LE. The Diseases of Infancy and Childhood. New York, NY: D. Appleton and $\mathrm{Co} ; 1897: 644650$.

2. Rittig S, Knudsen UB, Nørgaard JP, et al. Abnormal diurnal rhythm of plasma vasopressin and urinary output in pa- 


\section{The American Experience with Desmopressin}

tients with enuresis. Am J Physiol. 1989;256:F664-F671

3. Becker DJ, Foley TP Jr. 1-Deamino-8-Darginine vasopressin in the treatment of central diabetes insipidus in childhood. J Pediatr. 1978;92(6):1011-1018.

4. Tuvemo T. DDAVP in childhood nocturnal enuresis. Acta Pediatr Scand. 1978;67:753-755.

5. Birkásová M, Birkás O, Flynn MJ, Cort JH. Desmopressin in the management of nocturnal enuresis in children: a double-blind study. Pediatrics. 1978;62(6):970-974.

6. Rushton HG. Nocturnal enuresis: epidemiology, evaluation, and currently available treatment options. $J$ Pediatr. 1989;114 (4, pt 2): 691-696.

7. Post EM, Richman RA, Blackett PR, Duncan KP, Miller K. Desmopressin response of enuretic children. Am J Dis
Child. 1983;137:962-963.

8. Klauber GT. Clinical efficacy and safety of desmopressin in the treatment of nocturnal enuresis. $J$ Pediatr. 1989;114(4, pt 2):719-722.

9. Miller K, Goldberg S, Atkin B. Nocturnal enuresis: experience with long-term use of intranasally administered desmopressin. $J$ Pediatr. 1989; (4, pt 2) 114:723-726.

10. Miller K, Klauber GT. Desmopressin acetate in children with severe primary nocturnal enuresis. Clin Ther. 1990;12(4):357-366.

11. Miller K, Atkin B, Moody ML. Drug therapy for nocturnal enuresis. Current treatment recommendations. Drugs. 1992;44(1):47-56.

12. Key DW, Bloom DA, Sanvordenker J. Low-dose desmopressin in nocturnal enuresis. Clin Pediatr. 1992;39:299-301.
13. Simmonds EJ, Mahony MJ, Littlewood JM. Convulsion and coma after intranasal desmopressin in cystic fibrosis. BMJ. 1988;297:1614.

14. Bamford MFM, Cruickshank G. Dangers of intranasal desmopressin for nocturnal enuresis. $J R$ Coll Gen Pract. August 1989;345-346. Letter.

15. Salvatoni A, Maghnie $M$, Lorini $R$, Marni E. Hyponatremia and seizures during desmopressin acetate treatment in hypothyroidism. $J$ Pediatr. 1990; 116:835-836. Letter.

16. Bloom DA, Seeley WW, Richey ML, McGuire EJ. Toilet habits and continence in children: an opportunity sampling in search of normal parameters. $J$ Urol. 1993. In press.

17. Williams WC. In the American Grain. New York, NY: New Directions;1956:7. 